Kocaeli Journal of Science and Engineering

\title{
Design, Analysis and Simulation of a 6-DOF Serial Manipulator
}

\author{
Zehranur YILMAZ $^{1, *}$ (D), Orkun YILMAZ ${ }^{2}$ (D) Zafer BINGÜL $^{3}$ (D) \\ ${ }^{1}$ Department of Mechatronics Engineering, Kocaeli University, Kocaeli, 41310, Turkey, ORCID: 0000-0003-1930-6694 \\ ${ }^{2}$ Department of Mechatronics Engineering, Kocaeli University, Kocaeli, 41310, Turkey, ORCID: 0000-0003-1539-0905 \\ ${ }^{3}$ Department of Mechatronics Engineering, Kocaeli University, Kocaeli, 41310, Turkey, ORCID: 0000-0002-9777-9203
}

Article Info
Research paper
Received : January 20, 2020
Accepted : May 31, 2020

\section{Keywords}

Dynamic Analysis

Jacobian

Kinematic Analysis

MATLAB/Simscape

PID Control

Trajectory Planning

\begin{abstract}
Within the scope of this study, firstly, the mechanical structure of a six-axis serial manipulator was designed. Forward kinematic analysis was made using the Denavit-Hartenberg method, which provides the transition between cartesian coordinates, that is, the linear and angular positions of the end-effector, and joint coordinates; joint angles and linear displacements. In addition, to obtain the relation between the speed of joint variables and the speed of end effector, Jacobian matrix was derived. Dynamic analysis of the system based on Lagrange-Euler mathematical model was acquired. After the design phase was carried out in three-dimensional environment, the physical system-based dynamic model was obtained by transferring this data to the MATLAB-Simscape environment. Inverse dynamic problem was solved to verificate the $3 \mathrm{D}$ design of robot and suitability of selected motors. To solve this problem, position, and velocity and acceleration trajectories was given to the dynamic model. As a result of this, each joint torques were obtained. The trajectories used in inverse dynamics were calculated using a fifth order polynomial function. Afterwards, in order to test the operation of the system in a simulated environment, PID based controller structures were applied to the dynamic model in MATLAB/Simulink simulation environment and forward dynamic problem was reviewed and discussed.
\end{abstract}

\section{Introduction}

With the increase in consumption in many areas in the 21 st century, the production capacity has been increased and the use of autonomous systems that can work continuously with high efficiency without getting tired is becoming widespread. Robots come first among the autonomous systems since they have the ability to perform various tasks. For this reason, the development of robots for use in the industry in our country can be described as an important technological step in the country's rise to the level of developed countries. The purpose of this study is to create a substructure to overcome this deficiency. In robot technology, many control methods are used to provide very precise and stable working cycles.

At the point of control of serial robots, PID based control methods [1] as well as many nonlinear control methods are also used [2-3]. Likewise, in [4] and [5],

* Corresponding Author: ylmz.zehranur@gmail.com control of the robot was carried out using evolutionary algorithms (PSO). It is a common approach to benefit from mathematical models when using these control methods. When performing dynamic analysis of robots, energybased models such as Lagrange-Euler [6-10] or forcebased models such as Newton-Euler [11] occupy a wide range in the literature. Whether the model created during the use of mathematical models fully meets the system is a very important criterion [12]. Although a mathematical model prepared by neglecting inputs such as real-time friction and actuator dynamics into the control system and dynamic analysis based on this model seems to be an ideal system in the simulation environment, it is far from real time. Modeling of a robot designed in three-dimensional environment through Simscape in Simulink environment has been adopted as an effective approach to obtain the physical component and physical connection data of the robot very close to real time. Simscape based modeling has many uses; PV generators in microgrid scenario [13], power PIN diodes [14], wind turbine gearboxs [15], 3-RPS 
parallel robotics [16], 5-DOF robotic manipulators [17]. All body components and materials of the robot were selected according to the calculations made during the design phase. Forward and inverse kinematics problems, which provide the transition between cartesian coordinates, that is, the linear and angular positions of the gripper, and joint coordinates, i.e. joint angles and displacements are discussed. Forward and inverse kinematics problems that provide the transition between the Cartesian coordinates that is the linear and angular positions of the end effector, and joint coordinates, i.e. joint angles and joint displacements are discussed. Kinematic, Jacobian and dynamic analysis are given in Section 2. In Section 3, simulation results are shown. Finally, conclusion is shared in Section 4.

\section{Materials and Methods}

In this study, 6-DOF serial manipulator ZORO-1 was developed to be remotely controlled by a human that can fulfill tasks such as pick and place. As a result of this, ZORO-1 was designed based on the human arm and all of its joints were selected as revolute joints. Robot's 3D structure was modeled in Autodesk Inventor program which is shown in Figure 1.

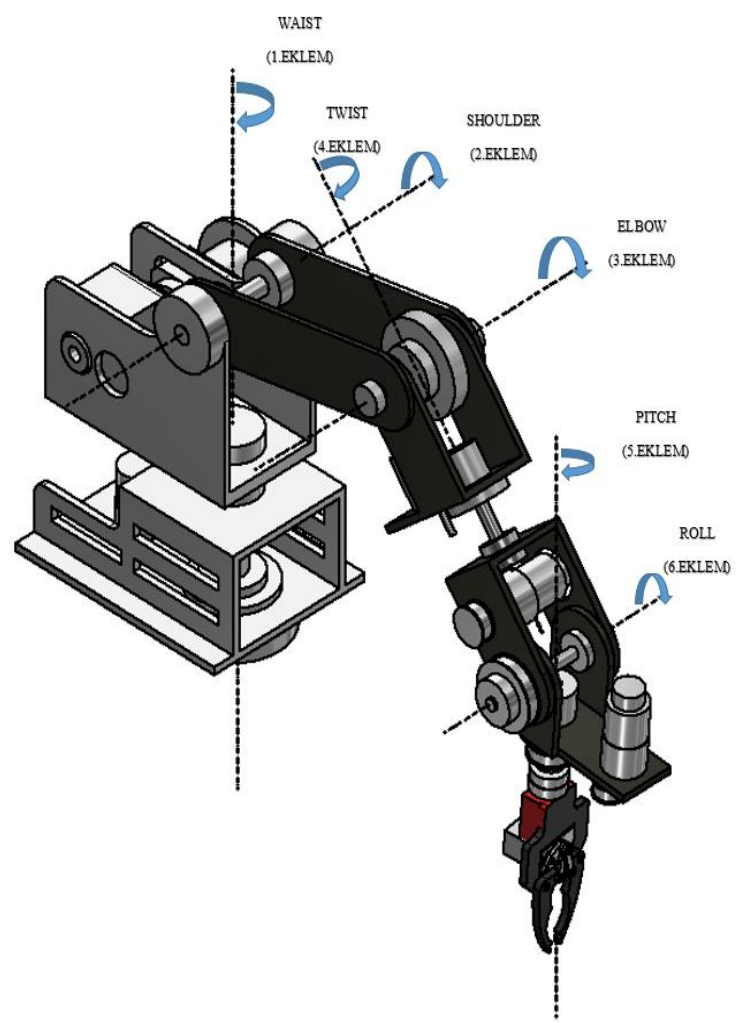

Figure 1. Mechanical structure of ZORO-1.

In the subsections below, the kinematic and dynamic model of ZORO-1 is presented. Evaluation of your work or to repeat the experiments exactly as you have done them.

\subsection{Kinematic Analysis}

In this study, Denavit-Hartenberg (DH) method was used to obtain the kinematic model of ZORO-1 robot. With DH method, the end effector's position and orientation data according to reference coordinate frame can be calculated parametrically in terms of joint variables. As the first step, cartesian coordinat frames were placed (Figure 2 ). Then the $\mathrm{DH}$ parameters of the robot were found and are shown in Table 1.

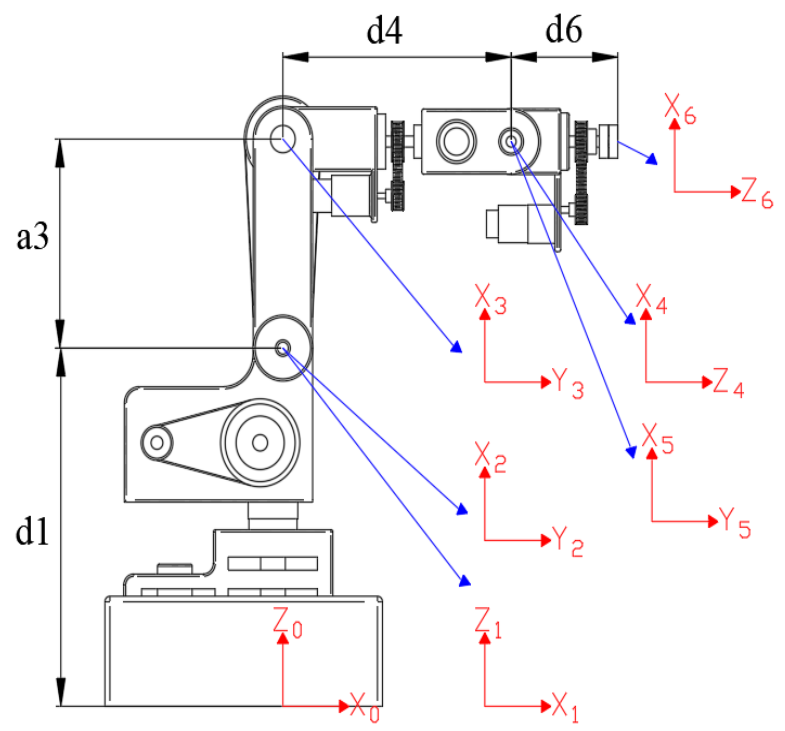

Figure 2. Cartesian coordinate frames of the robot.

Table 1. DH parameters of ZORO-1.

\begin{tabular}{|c|c|c|c|c|}
\hline $\mathrm{i}$ & $\alpha_{\mathrm{i}}(\mathrm{deg})$ & $\mathrm{a}_{\mathrm{i}}(\mathrm{m})$ & $\mathrm{d}_{\mathrm{i}}(\mathrm{m})$ & $\theta_{\mathrm{i}}(\mathrm{deg})$ \\
\hline 1 & $\alpha_{1}=0$ & $\mathrm{a}_{1}=0$ & $\mathrm{~d}_{1}=0.32$ & $\theta_{1}$ \\
\hline 2 & $\alpha_{2}=-90$ & $\mathrm{a}_{2}=0$ & $\mathrm{~d}_{2}=0$ & $\theta_{2}-90$ \\
\hline 3 & $\alpha_{3}=0$ & $\mathrm{a}_{3}=0.19$ & $\mathrm{~d}_{3}=0$ & $\theta_{3}$ \\
\hline 4 & $\alpha_{4}=-90$ & $\mathrm{a}_{2}=0$ & $\mathrm{~d}_{4}=0.23$ & $\theta_{4}$ \\
\hline 5 & $\alpha_{5}=90$ & $\mathrm{a}_{2}=0$ & $\mathrm{~d}_{5}=0$ & $\theta_{5}$ \\
\hline 6 & $\alpha_{6}=-90$ & $\mathrm{a}_{2}=0$ & $\mathrm{~d}_{6}=0.11$ & $\theta_{6}$ \\
\hline
\end{tabular}

Secondly, forward kinematic transformation matrices were derived using DH parameters in Eq. (1).

$$
{ }_{1}^{0} \mathrm{~T}=\left[\begin{array}{cccc}
\mathrm{c}_{1} & -\mathrm{s}_{1} & 0 & 0 \\
\mathrm{~s}_{1} & \mathrm{c}_{1} & 0 & 0 \\
0 & 0 & 1 & \mathrm{~d}_{1} \\
0 & 0 & 0 & 1
\end{array}\right], \quad{ }_{2}^{1} \mathrm{~T}=\left[\begin{array}{cccc}
\mathrm{s}_{2} & \mathrm{c}_{2} & 0 & 0 \\
0 & 0 & 1 & 0 \\
\mathrm{c}_{2} & -\mathrm{s}_{2} & 0 & 0 \\
0 & 0 & 0 & 1
\end{array}\right]
$$

$$
{ }_{3}^{2} \mathrm{~T}=\left[\begin{array}{cccc}
\mathrm{c}_{3} & -\mathrm{s}_{3} & 0 & \mathrm{a}_{3} \\
-\mathrm{s}_{3} & -\mathrm{c}_{3} & 0 & 0 \\
0 & 0 & 1 & 0 \\
0 & 0 & 0 & 1
\end{array}\right], \quad{ }_{4}^{3} \mathrm{~T}=\left[\begin{array}{cccc}
\mathrm{c}_{4} & -\mathrm{s}_{4} & 0 & 0 \\
0 & 0 & 1 & \mathrm{~d}_{4} \\
-\mathrm{s}_{4} & -\mathrm{c}_{4} & 0 & 0 \\
0 & 0 & 0 & 1
\end{array}\right]
$$


${ }_{5}^{4} \mathrm{~T}=\left[\begin{array}{cccc}\mathrm{c}_{5} & -\mathrm{s}_{5} & 0 & 0 \\ 0 & 0 & -1 & 0 \\ \mathrm{~s}_{5} & \mathrm{c}_{5} & 0 & 0 \\ 0 & 0 & 0 & 1\end{array}\right], \quad{ }_{6}^{5} \mathrm{~T}=\left[\begin{array}{cccc}\mathrm{c}_{6} & -\mathrm{s}_{6} & 0 & 0 \\ 0 & 0 & 1 & \mathrm{~d}_{6} \\ -\mathrm{s}_{6} & \mathrm{c}_{6} & 0 & 0 \\ 0 & 0 & 0 & 1\end{array}\right]$

where $s_{i}$ and $c_{i}$ represent $\sin \theta_{i}$ and $\cos \theta_{i}$ respectively. To calculate the transformation matrix ${ }_{6}^{0} \mathrm{~T}$ was used in Eq. (2):

${ }_{6}^{0} \mathrm{~T}={ }_{1}^{0} \mathrm{~T}_{2}^{1} \mathrm{~T}_{3}^{2} \mathrm{~T}_{4}^{3} \mathrm{~T}_{5}^{4} \mathrm{~T}_{6}^{5} \mathrm{~T}$

In Eq. (3) all row and column of ${ }_{6}^{0} \mathrm{~T}$ matrix elements were demonstrated:

${ }_{6}^{0} \mathrm{~T}(1,1)=-\mathrm{c}_{1} \mathrm{~s}_{23} \mathrm{~s}_{4} \mathrm{~s}_{6}+\mathrm{s}_{1} \mathrm{c}_{4} \mathrm{~s}_{6}+\mathrm{s}_{1} \mathrm{~s}_{4} \mathrm{c}_{5} \mathrm{c}_{6}+\mathrm{c}_{1} \mathrm{~s}_{23} \mathrm{c}_{4} \mathrm{c}_{5} \mathrm{c}_{6}+\mathrm{c}_{1} \mathrm{c}_{23} \mathrm{~s}_{5} \mathrm{c}_{6}$

${ }_{6}^{0} \mathrm{~T}(2,1)=-\mathrm{c}_{1} \mathrm{c}_{4} \mathrm{~s}_{6}-\mathrm{s}_{1} \mathrm{~s}_{23} \mathrm{~s}_{4} \mathrm{~s}_{6}-\mathrm{c}_{1} \mathrm{~s}_{4} \mathrm{c}_{5} \mathrm{c}_{6}+\mathrm{s}_{1} \mathrm{~s}_{23} \mathrm{c}_{4} \mathrm{c}_{6}+\mathrm{s}_{1} \mathrm{c}_{23} \mathrm{~s}_{3} \mathrm{c}_{6}$

${ }_{6}^{0} \mathrm{~T}(3,1)=\mathrm{c}_{23} \mathrm{c}_{4} \mathrm{c}_{5} \mathrm{c}_{6}-\mathrm{s}_{23} \mathrm{~s}_{5} \mathrm{~s}_{6}-\mathrm{c}_{23} \mathrm{~s}_{4} \mathrm{~s}_{6}$

${ }_{6}^{0} \mathrm{~T}(1,2)=-\mathrm{s}_{1} \mathrm{c}_{4} \mathrm{c}_{6}-\mathrm{c}_{1} \mathrm{~s}_{23} \mathrm{~s}_{4} \mathrm{c}_{6}-\mathrm{s}_{1} \mathrm{~s}_{4} \mathrm{c}_{5} \mathrm{~s}_{6}-\mathrm{c}_{1} \mathrm{~s}_{23} \mathrm{c}_{4} \mathrm{c}_{5} \mathrm{~s}_{6}-\mathrm{c}_{1} \mathrm{c}_{23} \mathrm{~s}_{5} \mathrm{~s}_{6}$

${ }_{6}^{0} \mathrm{~T}(2,2)=\mathrm{c}_{1} \mathrm{~s}_{4} \mathrm{c}_{5} \mathrm{~s}_{6}-\mathrm{s}_{1} \mathrm{~s}_{23} \mathrm{c}_{4} \mathrm{~s}_{6}-\mathrm{s}_{1} \mathrm{c}_{23} \mathrm{~s}_{5}-\mathrm{c}_{1} \mathrm{c}_{4} \mathrm{c}_{6}-\mathrm{s}_{1} \mathrm{~s}_{23} \mathrm{~s}_{4} \mathrm{c}_{6}-\mathrm{c}_{1} \mathrm{c}_{4} \mathrm{c}_{6}$

$\left.{ }_{6}^{0} \mathrm{~T}(3,2)=\mathrm{s}_{23} \mathrm{~s}_{5} \mathrm{~s}_{6}-\mathrm{c}_{23} \mathrm{c}_{4} \mathrm{c}_{5} \mathrm{~s}_{6}-\mathrm{c}_{23} \mathrm{~s}_{4} \mathrm{c}_{6}\right)$

${ }_{6}^{0} \mathrm{~T}(1,3)=-\mathrm{c}_{1} \mathrm{c}_{23} \mathrm{c}_{5}-\mathrm{s}_{1} \mathrm{~s}_{4} \mathrm{~s}_{5}-\mathrm{c}_{1} \mathrm{~s}_{23} \mathrm{c}_{4} \mathrm{~s}_{5}$

${ }_{6}^{0} \mathrm{~T}(2,3)=\mathrm{c}_{1} \mathrm{~s}_{4} \mathrm{~s}_{5}-\mathrm{s}_{1} \mathrm{~s}_{23} \mathrm{c}_{4} \mathrm{~s}_{5}-\mathrm{s}_{1} \mathrm{c}_{23} \mathrm{c}_{5}$

${ }_{6}^{0} \mathrm{~T}(3,3)=-\mathrm{s}_{23} \mathrm{c}_{5}-\mathrm{c}_{23} \mathrm{c}_{4} \mathrm{~s}_{5}$

${ }_{6}^{0} \mathrm{~T}(1,4)=\mathrm{a}_{3} \mathrm{c}_{1} \mathrm{~s}_{2}+\mathrm{d}_{4} \mathrm{c}_{1} \mathrm{c}_{23}-\mathrm{d}_{6}\left(\mathrm{~s}_{1} \mathrm{~s}_{4} \mathrm{~s}_{5}+\mathrm{c}_{1} \mathrm{~s}_{23} \mathrm{c}_{4} \mathrm{~s}_{5}-\mathrm{c}_{1} \mathrm{c}_{23} \mathrm{c}_{5}\right)$

${ }_{6}^{0} \mathrm{~T}(2,4)=\mathrm{a}_{3} \mathrm{~s}_{1} \mathrm{~s}_{2}+\mathrm{d}_{4} \mathrm{~s}_{1} \mathrm{c}_{23}+\mathrm{d}_{6}\left(\mathrm{c}_{1} \mathrm{~s}_{4} \mathrm{~s}_{5}-\mathrm{s}_{1} \mathrm{~s}_{23} \mathrm{c}_{4} \mathrm{~s}_{5}\right)$

${ }_{6}^{0} \mathrm{~T}(3,4)=\mathrm{d}_{1}+\mathrm{a}_{3} \mathrm{c}_{2}-\mathrm{d}_{4} \mathrm{~s}_{23}-\mathrm{d}_{6}\left(\mathrm{~s}_{23} \mathrm{c}_{5}+\mathrm{c}_{23} \mathrm{c}_{4} \mathrm{~s}_{5}\right)$

where $\mathrm{s}_{\mathrm{ij}}$ and $\mathrm{c}_{\mathrm{ij}}$ represent $\sin \left(\theta_{\mathrm{i}}+\theta_{\mathrm{j}}\right)$ and $\cos \left(\theta_{\mathrm{i}}+\theta_{\mathrm{j}}\right)$ respectively.

\subsection{Jacobian Analysis}

The Jacobian matrix provides the transition between the velocity of the joint variables and the linear and angular velocities of the end effector. The dimension of this matrix is $6 \mathrm{xn}$, where $\mathrm{n}$ represents the number of joint variables. While $\mathrm{J}_{\mathrm{v}}$, which constitutes the first three lines and relates to linear velocities, was calculated by the direct derivations of the position vectors, last three lines $\mathbf{J}_{\omega}$, which relates to angular velocitis, was taken from the relevant part in the rotation matrices in Eq. (4), Eq. (5), and Eq. (6);

$\mathrm{J}=\left[\begin{array}{l}\mathrm{J}_{\mathrm{v}} \\ \mathrm{J}_{\omega}\end{array}\right]$

$\mathrm{J}_{\mathrm{V}}=\left[\begin{array}{llll}\frac{\partial \mathrm{p}_{\mathrm{x}}}{\partial \mathrm{q}_{1}} & \frac{\partial \mathrm{p}_{\mathrm{x}}}{\partial \mathrm{q}_{2}} & \frac{\partial \mathrm{p}_{\mathrm{x}}}{\partial \mathrm{q}_{\mathrm{n}-1}} & \frac{\partial \mathrm{p}_{\mathrm{x}}}{\partial \mathrm{q}_{\mathrm{n}}} \\ \frac{\partial \mathrm{p}_{\mathrm{y}}}{\partial \mathrm{q}_{1}} & \frac{\partial \mathrm{p}_{\mathrm{y}}}{\partial \mathrm{q}_{2}} & \cdots \frac{\partial \mathrm{p}_{\mathrm{y}}}{\partial \mathrm{q}_{\mathrm{n}-1}} & \frac{\partial \mathrm{p}_{\mathrm{y}}}{\partial \mathrm{q}_{\mathrm{n}}} \\ \frac{\partial \mathrm{p}_{\mathrm{z}}}{\partial \mathrm{q}_{1}} & \frac{\partial \mathrm{p}_{\mathrm{z}}}{\partial \mathrm{q}_{2}} & \frac{\partial \mathrm{p}_{\mathrm{z}}}{\partial \mathrm{q}_{\mathrm{n}-1}} & \frac{\partial \mathrm{p}_{\mathrm{z}}}{\partial \mathrm{q}_{\mathrm{n}}}\end{array}\right]$

$\mathrm{J}_{\omega}=\left[{ }_{1}^{0} \mathrm{R} \widehat{Z}_{1} \xi_{1} \quad{ }_{2}^{0} \mathrm{R} \widehat{Z}_{2} \xi_{2} \cdots{ }_{\mathrm{n}-1}^{0} \mathrm{R} \widehat{Z}_{\mathrm{n}-1} \xi_{\mathrm{n}-1}{ }_{\mathrm{n}}^{0} \mathrm{R} \widehat{Z}_{\mathrm{n}} \xi_{\mathrm{n}}\right]$

The rotational and translational Jacobian matrices were obtained as;

where $\widehat{Z}_{i}$ is $\left[\begin{array}{lll}0 & 0 & 1\end{array}\right]^{\mathrm{T}}$ vector and $\xi_{\mathrm{i}}$ is a coefficient which indicates the joint type and for rotational joints it's " 1 ", for prismatic joints it's " 0 ". The relationship between joint space and cartesian space speeds can be given as Eq. (7):

$\dot{\mathrm{x}}=\mathrm{J} \dot{\mathrm{q}}$

where $\dot{\mathrm{x}}=\left[\begin{array}{c}\mathrm{u}_{\mathrm{x}} \\ \mathrm{u}_{\mathrm{y}} \\ \mathrm{u}_{\mathrm{z}} \\ \omega_{\mathrm{x}} \\ \omega_{\mathrm{y}} \\ \omega_{\mathrm{z}}\end{array}\right], \dot{\mathrm{q}}=\left[\begin{array}{c}\dot{\mathrm{q}}_{1} \\ \dot{\mathrm{q}}_{2} \\ \vdots \\ \dot{\mathrm{q}}_{\mathrm{n}-1} \\ \dot{\mathrm{q}}_{\mathrm{n}}\end{array}\right]$.

\subsection{Dynamic Analysis}

In this subsection, the dynamic model of ZORO-1 robot is discussed. Dynamics is the field of science that studies the motions of objects under a cause and effect relationship with the forces applied to them. In this study, Lagrange-Euler equations were used to obtain the dynamic model. This method is an energy-based approach. Firstly, Lagrangian (L) must be found using the total kinetic $(\mathrm{K})$ and potential (P) energies of the system Eq. (8).

$L(q, \dot{q})=K(q, \dot{q})-P(q)$

Thus, the equations of the motion could be obtained as in Eq. (7);

$\frac{\mathrm{d}}{\mathrm{dt}}\left(\frac{\partial \mathrm{L}}{\partial \dot{\mathrm{q}}}\right)-\frac{\partial \mathrm{L}}{\partial \mathrm{q}}=\tau$

where $\mathrm{q}$ and $\tau$ are joint variables and torques respectively. 
By using Eq. (9) the general robotic dynamic equation can be derived as in Eq. (10);

$D(q) \ddot{q} C(q, \dot{q})+G(q)=\tau$

while $\mathrm{D}$ is the mass matrix which contains the inertial forces, $\mathrm{C}$ is the coriolis vector. $\mathrm{G}$ is the gravity vector which hosts the gravitational forces. follows;

The total kinetic energy of a system can be given as

$\mathrm{K}(\mathrm{q}, \dot{\mathrm{q}})=\frac{1}{2} \sum_{\mathrm{i}=1}^{\mathrm{n}}\left(\mathrm{V}_{\mathrm{i}}\right)^{\mathrm{T}} \mathrm{m}_{\mathrm{i}} \mathrm{V}_{\mathrm{i}}+\left(\omega_{\mathrm{i}}\right)^{\mathrm{T}} \mathrm{I}_{\mathrm{i}} \omega_{\mathrm{i}}$

In Eq. (11), $\mathrm{m}_{\mathrm{i}}$ and $\mathrm{I}_{\mathrm{i}}$ are the mass and inertia matrix of i-th link respectively. Cartesian velocities can be written in terms of joint velocities by using Jacobian as follows;

$\mathrm{V}_{\mathrm{i}}=\mathrm{J}_{\mathrm{v}} \dot{\mathrm{q}}, \quad \omega_{\mathrm{i}}=\mathrm{J}_{\omega} \dot{\mathrm{q}}$

Substituting Eq. (12) into Eq. (11) yields;

$\mathrm{K}(\mathrm{q}, \dot{\mathrm{q}})=\frac{1}{2} \dot{\mathrm{q}}^{\mathrm{T}} \sum_{\mathrm{i}=1}^{\mathrm{n}}\left[\left(\mathrm{J}_{\mathrm{v}_{\mathrm{i}}}\right)^{\mathrm{T}} \mathrm{m}_{\mathrm{i}} \mathrm{J}_{\mathrm{v}_{\mathrm{i}}}+\left(\mathrm{J}_{\omega_{\mathrm{i}}}\right)^{\mathrm{T}} \mathrm{I}_{\mathrm{i}} \mathrm{J}_{\omega_{\mathrm{i}}}\right] \dot{\mathrm{q}}$

In this equation, the part in brackets is the mass matrix. By using the below Eqs. (14-15) coriolis vector in Eq. (16) can be obtained from mass matrix;

$\mathrm{D}(\mathrm{q})=\left[\left(\mathrm{J}_{\mathrm{v}_{\mathrm{i}}}\right)^{\mathrm{T}} \mathrm{m}_{\mathrm{i}} \mathrm{J}_{\mathrm{v}_{\mathrm{i}}}+\left(\mathrm{J}_{\omega_{\mathrm{i}}}\right)^{\mathrm{T}} \mathrm{I}_{\mathrm{i}} \mathrm{J}_{\omega_{\mathrm{i}}}\right]$

$\mathrm{C}(\mathrm{q}, \dot{\mathrm{q}})=\sum_{\mathrm{k}=1}^{\mathrm{n}} \sum_{\mathrm{j}=1}^{\mathrm{n}}\left[\mathrm{c}_{\mathrm{kj}}^{\mathrm{i}}(\mathrm{q}) \dot{\mathrm{q}}_{\mathrm{k}} \dot{\mathrm{q}}_{\mathrm{j}}\right]$

$c_{k j}^{i}(q)=\frac{\partial}{\partial q_{k}} D_{i j}(q)-\frac{1}{2} \frac{\partial}{\partial q_{i}} D_{k j}(q), 1 \leq i, j, k \leq n$

And finally G vector can be derived by Eq. (17);

$G(q)=-\sum_{k=1}^{n} \sum_{j=1}^{n}\left[g_{k} m_{j} A_{k i}^{j}(q)\right]$

Gravity matrix elements were given in Eqs. (18-22);

$\mathrm{G}(1)=0$

$\mathrm{G}(2)=\frac{1}{2} \mathrm{~g}\left(\frac{\mathrm{m}_{5}}{200}\left(\mathrm{c}_{23} \mathrm{~d}_{4}+\mathrm{a}_{3} \mathrm{~s}_{2}+\mathrm{d}_{6} \mathrm{c}_{23} \mathrm{~s}_{5}+\mathrm{d}_{6} \mathrm{~s}_{23} \mathrm{c}_{4} \mathrm{c}_{5}\right)+\right.$

$\mathrm{m}_{4}\left(\mathrm{~d}_{4} \mathrm{c}_{23}-\frac{9}{200} \mathrm{c}_{23}+\mathrm{a}_{3} \mathrm{~s}_{2}\right)+\mathrm{m}_{3}\left(\frac{9}{200} \mathrm{c}_{23}+\mathrm{a}_{3} \mathrm{~s}_{2}\right)+$
$\mathrm{G}(3)=\mathrm{g}\left(\frac{9}{200} \mathrm{~m}_{3} \mathrm{c}_{23} \mathrm{~d}_{4}+\mathrm{m}_{5} \mathrm{~d}_{4} \mathrm{c}_{23}+\frac{1}{2} \mathrm{~d}_{6}\left(\mathrm{c}_{23} \mathrm{~s}_{5}+\mathrm{s}_{23} \mathrm{c}_{4} \mathrm{c}_{5}\right)-\right.$

$\mathrm{m}_{4}\left(\frac{9}{200} \mathrm{c}_{23} \mathrm{~d}_{4}+\mathrm{d}_{4} \mathrm{c}_{23}\right)$

$\mathrm{G}(4)=\frac{1}{2} \mathrm{gm}_{5} \mathrm{~d}_{6} \mathrm{c}_{23} \mathrm{~s}_{4} \mathrm{c}_{5}$

$\mathrm{G}(5)=\frac{1}{2} \mathrm{gm}_{5} \mathrm{~d}_{6}\left(\mathrm{~s}_{23} \mathrm{c}_{5}+\mathrm{c}_{23} \mathrm{c}_{4} \mathrm{~s}_{5}\right)$

The inertial parameters of ZORO-1 robot which were taken from Inventor program are shown in Figure 3. These parameters were used to obtain the simulation results in MATLAB/Simulink.

First, inverse dynamics problem was discussed. In this problem, joint torques can be calculated by giving trajectories of position, velocity and acceleration of all joints to dynamic model. Inverse dynamic analysis is used for verification of mechanical model and motor selection.

Forward dynamics analysis was made to simulate ZORO-1 robot. To control the robot a PID controller was created and adapted to dynamic model. Both forward and inverse dynamics simulation results are given in Section 3.

\subsection{Trajectory Planning}

In this study, for achieving the solution of inverse dynamics trajectory planning has been made. A fifth order polynomial was used in position trajectory which is given below;

${ }_{\theta}(t)=s_{0}+s_{1} t+s_{2} t^{2}+s_{3} t^{3}+s_{4} t^{4}+s_{5} t^{5}$

$\dot{\theta}_{\theta}(t)=s_{1}+2 s_{2} t+3 s_{3} t^{2}+4 s_{4} t^{3}+5 s_{5} t^{4}$

$\ddot{\theta}(t)=2 s_{2}+6 s_{3} t+12 s_{4} t^{2}+20 s_{5} t^{3}$

where;

$$
\begin{aligned}
& \mathrm{s}_{0}=\theta_{\theta_{0}}, \quad \mathrm{~s}_{1}=\dot{\theta}_{0}, \\
& \mathrm{~s}_{3}=\frac{20\left(\theta_{\theta_{\mathrm{r}}-\theta_{0}}\right)-\left(\dot{\theta}_{\mathrm{f}}+12 \dot{\theta}_{0}\right) \mathrm{t}_{\mathrm{f}}+\left(\ddot{\theta}_{\mathrm{r}}-3 \ddot{\theta}_{0}\right) \mathrm{t}_{\mathrm{f}}{ }^{2}}{{ }_{2} \mathrm{t}_{\mathrm{f}}^{3}},
\end{aligned}
$$

$\mathrm{s}_{4}=\frac{30\left(\theta_{\theta_{0}-\theta_{\mathrm{f}}}\right)+\left(14 \dot{\theta}_{\mathrm{f}}+16 \dot{\theta}_{0}\right) \mathrm{t}_{\mathrm{f}}+\left(\ddot{\theta}_{3}-2 \ddot{\theta}_{\mathrm{f}}\right) \mathrm{t}_{\mathrm{f}}^{2}}{{ }_{2} \mathrm{t}_{\mathrm{f}}^{4}}$,

$\mathrm{s}_{5}=\frac{12\left(\theta_{\mathrm{r}}-\theta_{0}\right){ }_{-6}\left(\dot{\theta}_{\mathrm{r}}+\dot{\theta}_{0}\right) \mathrm{t}_{\mathrm{f}}-\left(\ddot{\theta}_{0}-\ddot{\theta}_{\mathrm{r}}\right) \mathrm{t}_{\mathrm{f}}^{2}}{{ }_{2} \mathrm{t}_{\mathrm{f}}^{5}}$. $\left(\frac{1}{2} \mathrm{a}_{3} \mathrm{~m}_{2} \mathrm{~s}_{2}\right)$ ) 


\begin{tabular}{|c|c|c|c|c|c|c|c|c|c|c|c|c|c|c|}
\hline \multicolumn{3}{|c|}{$\begin{array}{c}\text { Center of mass } \\
\text { expressed in base } \\
\text { coordinate frame/(m) }\end{array}$} & \multicolumn{9}{|c|}{$\begin{array}{l}\text { Moment of inertial for center of mass and } \\
\text { expressed in center of mass coordinate frame } /\left(\mathrm{kg}-m^{2}\right)\end{array}$} & \multirow{2}{*}{$\begin{array}{c}\text { Part } \\
\text { mass/ } \\
\mathrm{kg}\end{array}$} & \multirow{2}{*}{$\begin{array}{c}\text { Moving } \\
\text { Part } \\
\text { Number }\end{array}$} & \multirow{2}{*}{$\begin{array}{l}\text { Moving part of } \\
\text { ZORO-1 } \\
\text { robot } \\
\text { designed by } \\
\text { Inventor }\end{array}$} \\
\hline$x$ & $\mathrm{y}$ & $z$ & $I_{x x}$ & $I_{x y}$ & $I_{x z}$ & $I_{y x}$ & $I_{y y}$ & $I_{y z}$ & $I_{z x}$ & $I_{z y}$ & $I_{z z}$ & & & \\
\hline-0.01 & 0.03 & 0 & 0.03 & 0.001 & 0.001 & 0.001 & 0.01 & -0.003 & 0.001 & -0.003 & 0.026 & 3.78 & Part1 & \\
\hline 0 & 0 & 0.02 & 0.003 & 0 & 0 & 0 & 0.003 & 0 & 0 & 0 & 0.0008 & 0.52 & Part2 & \\
\hline 0.008 & 0.056 & -0.001 & 0.0017 & -0.0003 & 0 & -0.0003 & 0.001 & 0 & 0 & 0 & 0.002 & 0.84 & Part3 & \\
\hline 0 & -0.017 & 0.04 & 0.0005 & 0 & 0 & 0 & 0.0002 & 0 & 0 & 0 & 0.0004 & 0.24 & Part4 & \\
\hline-0.02 & 0.003 & 0.03 & 0.0007 & 0 & 0 & 0 & 0.0012 & 0 & 0 & 0 & 0.0012 & 0.62 & Part5 & \\
\hline 0 & 0 & 0.017 & 0 & 0 & 0 & 0 & 0 & 0 & 0 & 0 & 0 & 0.066 & Part6 & \\
\hline
\end{tabular}

Figure 3. Inertia tensor elements and masses of moving part of ZORO-1 robot.

\section{Simulation Results}

In this study, two dynamic problems were solved for ZORO-1 robot.

\subsection{Inverse Dynamic Problem}

First of all, to solve the inverse dynamics problem, position, velocity and acceleration trajectories of all joints were given to the dynamic model and as a result of this joint torques were calculated. This analysis was done for verification of $3 \mathrm{D}$ model of robot and motor selection. The trajectories are given in Figures 4-6, respectively.

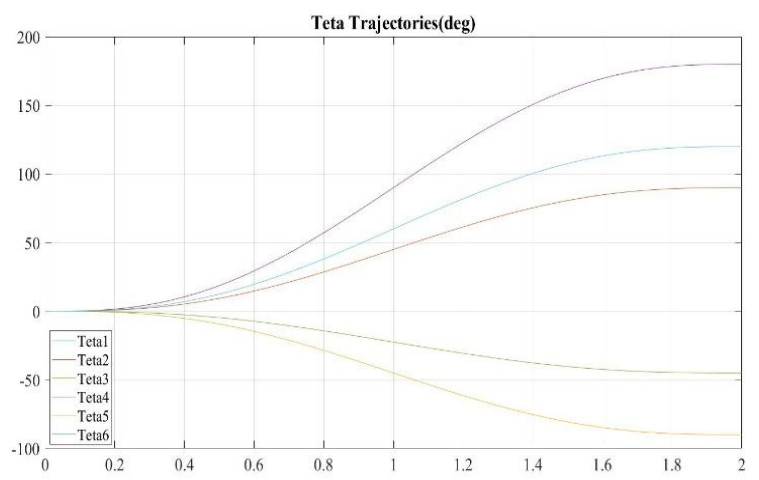

Figure 4. Position trajectories.

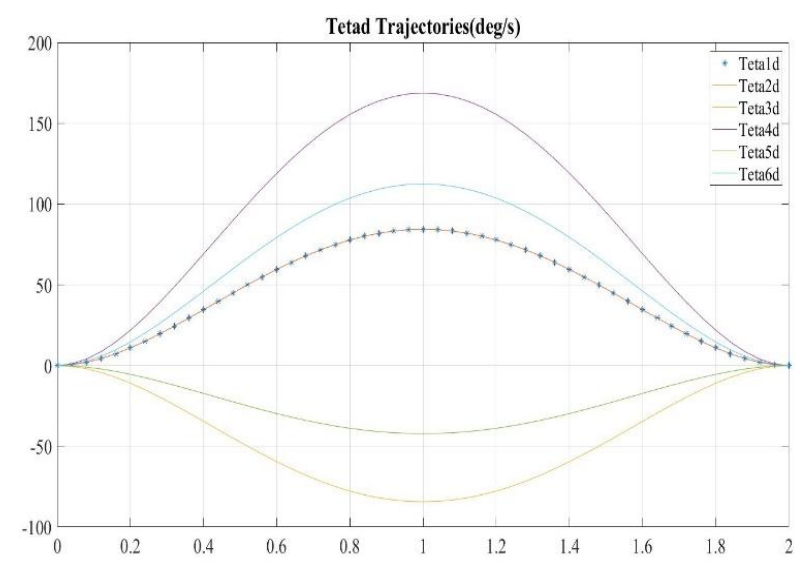

Figure 5. Velocity trajectories.

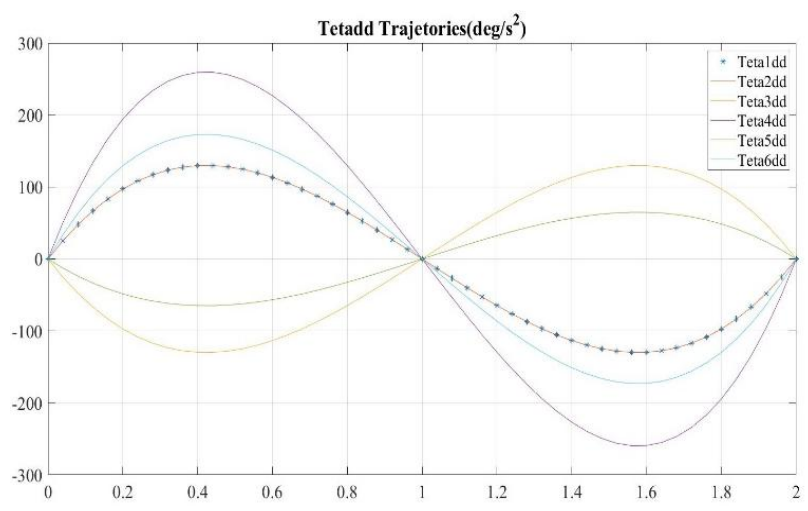

Figure 6. Acceleration trajectories. 
Calculated torques for each joint for given trajectories are also given in Figure 7.

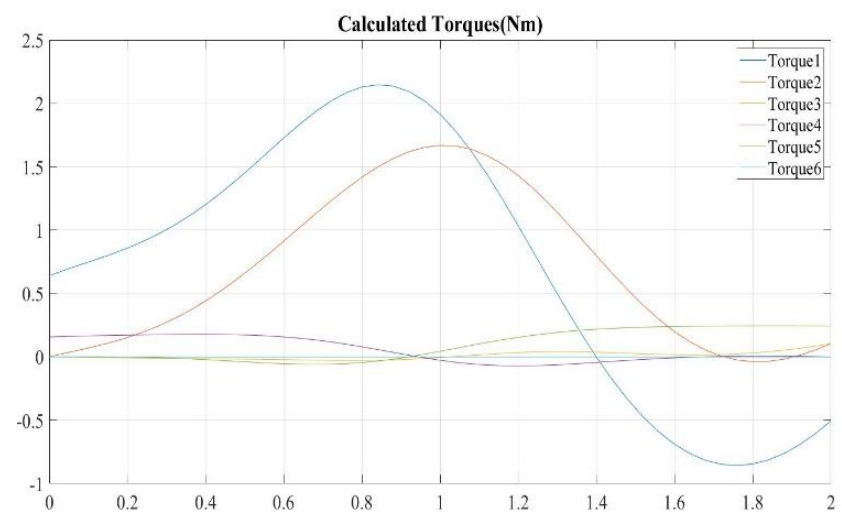

Figure 7. Calculated torques.

After results were viewed, mechanical model and selected motors were verified.

\subsection{Forward Dynamic Results}

In this subsection, a PID based controller was created and connected to dynamic model. For controlling the joint variables a simulation was developed. In Figure 8, joint variables-time graphs were shown via their reference signals and the controller signals are given in Figure 9.
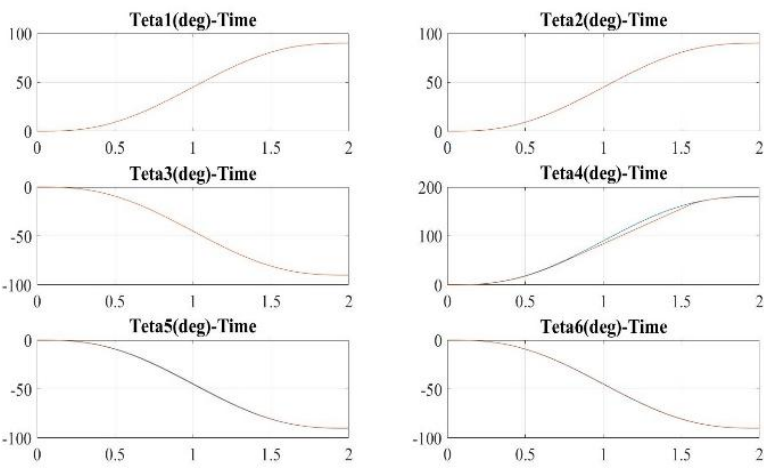

Figure 8. Joint variables-time graphics.

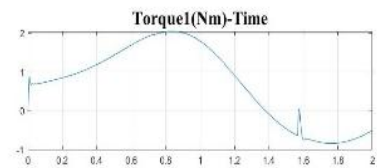

Torque3(Nm)-Time

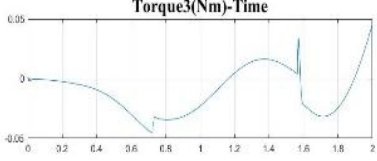

Torques(Nm)-Tim

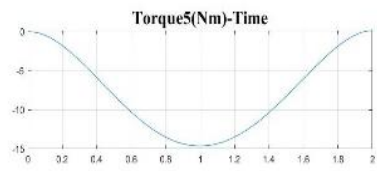

Figure 9. Controller signals in Simscape simulation.
Desired trajectory tracing for ZORO-1 robot was achieved with developed PID controller with considering limitations in motor torques.

\section{Conclusions}

In this article, firstly, the mechanical design of the ZORO-1 robot was realized. Since the robot developed in future studies will be focused on remote control with a Human-Machine Interface (HMI), the human arm is taken as the design stage of the robot in order to avoid any problems in compatibility. Kinematic, dynamic and Jacobian analyses of the developed robot were made. As a result of these studies, the system was transferred to the MATLAB-Simscape environment. The suitability of the 3D design and actuators of the robot developed in the first stage was evaluated. For this, the inverse dynamic problem is dealt with in the MATLAB-Simulink environment. The system has been verified because the torque values calculated in this direction can be provided by the motors actually selected. In the following stage, a PID based controller has been developed and adapted to this dynamic model and the system has been simulated in MATLABSimulink environment. It was determined that the desired control was achieved as a result of the simulation.

\section{References}

[1] Zhang D., Wei B., 2016. Design of a Joint Control System for Serial Mechanical Arms Based on PID and MRAC Control. Asia-Passific Conference on Intelligent Robot System, Tokyo, Japan, 20-22 July, pp. 91-96.

[2] Katliar M., Drop F. M., Teufel H., Diehl M., Bulthoff H. H., 2018. Real-Time Nonlinear Model Predictive Control of a Motion Simulator. 2018 Europian Control Conference (ECC), Limassol, South Cyprus, 12-15 June, doi: 10.23919/ECC.2018.8550041.

[3] Bingül Z., Karahan O., 2012. Fractional PID Controllers Tuned by Evolutionary Algorithms for Robot Trajectory Control. Turkish Journal of Electrical Engineering \& Computer Sciences, 20(Sup.1), 11231136.

[4] Bingül Z., Karahan O., 2011. A Fuzzy Logic Controller Tuned with PSO for 2 DOF Robot Trajectory Control. Expert Systems with Applications, doi: 10.1016/j.eswa.2010.07.131.

[5] Bingül Z., Varol H. A., 2004. A New PID Tuning Technique Using Ant Algorithm. Proceeding of the 2004 American Control Conference, Boston, Massachusetts, 30 June - 2 July. 
[6] Angeles J., 2007. Fundamentals of Robotic Mechanical Systems, Methods and Algorithms. Springer Science+Business Media LLC, 3rd ed., New York, NY, USA.

[7] Murray R. M, Li Z., Sastry S. S., 1994. A Mathematical Introduction to Robotic Manipulation, Berkeley: CRC Press, University of California.

[8] Dombre E., Khalil W., 2007. Modeling, Performance Analysis and Control of Robot Manipulators, ISTE Ltd., London, UK.

[9] Sciavicco L., Siciliano B., 2000. Modelling and Control of Robot Manipulators, Springer, London, UK.

[10] Siciliano B., Sciavicco L., Villani L., Oriolo G., 2009. Robotics: Modelling, Planning and Control, Springer, London, UK.

[11] Kunquan L., Rui W., 2011. Closed-form Dynamic Equetions of 6-RSS Parallel Mechanism Through the Newton-Euler Approach. Third International Conference on Measuring Technology and Mechatronics Automation, Henan Engineering Institute, Zhengzhou, China, 6-7 January, pp. 712-715.

[12] Wikipedians, 2019. Mathematical model, Wikipedia, https://en.wikipedia.org/wiki/Mathematical_model. (Access Date: 02 December 2019).

[13] Basak P., Chowdhury S., Chowdhury S. P., 2013. Simscape Based Modeling and Simulation of a PV Generator in Microgrid Scenario. 22nd International Conference and Exhibition on Electricity Distribution (CIRED), Stockholm, Sweden, 10-13 June, paper no: 0997.

[14] Elwarraki E., Mijlad N., Elbacha A., 2016. SIMSCAPE Electro-thermal Modelling of the PIN Diode for Power Circuits Simulation. IET Power Electronics, 9(7), pp. 1521-1526.

[15] Al-Hamadani H., An T., King M., Long H., 2017. System Dynamic Modelling of Three Different Wind Turbine Gearbox Designs Under Transient Loading Conditions. International Journal of Precision Engineering and Manufacturing, 18(11), pp. 16591668.

[16] Olaya J., Pintor N., Avilés O. F., Chaparro J., Analysis of 3 RPS Robotic Platform Motion in Simscape and MATLAB GUI Environment. International Journal of Applied Engineering Research, 12(8), pp. 1460-1468.

[17] Grazioso S., Di Maio M., Di Gironimo G., 2019. Conceptual Design, Control, and Simulation of a 5-DoF
Robotic Manipulator for Direct Additive Manufacturing on the Internal Surface of Radome Systems. The International Journal of Advanced Manufacturing Technology, 101(5-8), pp. 2027-2036. 